\title{
Spatial-Temporal Distribution of Summer Extreme Precipitation in South China and Response of Tropical Ocean
}

\author{
Xia Shi*, Ke Li, Mengzhou Yang, Xinyu Lu \\ Key Laboratory of Meteorological Disaster of Ministry of Education, Collaborative Innovation Center on Forecast and Evaluation \\ of Meteorological Disasters, Nanjing University of Information Science and Technology, Nanjing, China \\ Email: ^jing6696623@qq.com
}

How to cite this paper: Shi, X., Li, K., Yang, M. Z., \& Lu, X. Y. (2021). Spatial-Temporal Distribution of Summer Extreme Precipitation in South China and Response of Tropical Ocean. Journal of Geoscience and Environment Protection, 9, 249-261.

https://doi.org/10.4236/gep.2021.93015

Received: March 2, 2021

Accepted: March 27, 2021

Published: March 30, 2021

Copyright $\odot 2021$ by author(s) and Scientific Research Publishing Inc. This work is licensed under the Creative Commons Attribution International License (CC BY 4.0).

http://creativecommons.org/licenses/by/4.0/

\begin{abstract}
In the study, the summer extreme precipitation in South China is divided into early rainy season (MJ) and late rainy season (JA). The percentile method $(95 \%)$ is used to define the extreme precipitation threshold. Based on the international general definition method of extreme precipitation threshold: percentile method (95\%), the extreme precipitation thresholds in flood season before and after South China are defined respectively. The total amount and frequency of extreme precipitation in flood season before and after 1979-2014 are calculated in this paper. The change trend of the two indicators is basically the same, and the two indicators have obvious interannual variation and an upward trend. According to the results of wavelet analysis of extreme precipitation frequency, the frequency of extreme precipitation in the first flood season mainly has a period of 3 - 5 years, while the frequency of extreme precipitation in the later flood season has a significant period of $6-8$ years. The spatial distribution of extreme precipitation before and after the flood season shows that the extreme precipitation in the former flood season is mainly distributed in the central part of Guangdong, the northeast of Guangxi and the western part of Fujian, and the extreme precipitation in the latter flood season mainly occurs in the southern coastal area. The results show that there are different tropical SST regions affecting the extreme precipitation in South China. The former flood season is mainly the tropical Indian Ocean warm SST, and the latter flood season is mainly the tropical Pacific warm SST. The tropical Indian Ocean SST stimulates the anticyclonic anomaly over the South China Sea, which brings the southwest warm and humid air flow into South China, resulting in the increase of extreme precipitation in the first flood season of South China; the tropical Pacific SST stimulates the cyclonic anomaly over the South China Sea, which reduces the water vapor outflow
\end{abstract}


caused by the seasonal northward jump of the subtropical high in South China, resulting in the increase of extreme precipitation in the later flood season of South China.

\section{Keywords}

Extreme Precipitation, Extreme Precipitation Threshold, Early and Late Rainy Season, IOBM, ENSO

\section{Introduction}

Frequent occurrences of flooding are one of the most important meteorological disasters in China. South China is located in the southern coastal area of China, with a developed economy and a large population. It is one of the areas with the most precipitation in China. It has the characteristics of wide range, large intensity and long duration of precipitation. In addition, the precipitation in South China has obvious interannual variations, often causes the flood to cause the economic and the population loss. For example, floods in the summer of 1994 caused more than 40 billion yuan in economic losses in the two regions, affecting 60 million people, inundating 3.4 million hectares of rice fields and destroying 800,000 houses, and caused direct economic losses of about US $\$ 10$ billion $(\mathrm{Xu}, 1994)$. In view of the fact that flooding is often caused by extreme precipitation, the study of the characteristics of the temporal and spatial evolution of extreme precipitation and the response of the tropical SST will help to further understand the causes of the extreme precipitation in South China in summer and improve the techniques for predicting rainfall changes, it is of great social significance to enhance the ability of disaster prevention and reduction and to reduce the loss of people's lives and property.

South China is located in the East Asian monsoon region, affected by the monsoon, summer precipitation in South China can be divided into early rainy season and late rainy season. Previous studies usually defined April-June as the early rainy season in South China, July-September is the late rainy season (Liang \& Wu 2001; He \& Jin 1998; Wang et al., 2005). In fact, the onset of the Hainan monsoon usually marks the beginning of the East Asian summer monsoon (EASM; Lau \& Yang 1997; Wang \& Wu 1997; Zhu et al., 2005). The rainy season in South China usually lasts from May to August. Due to the characteristic of seasonal northward jump of East Asian summer monsoon, the rain belt formed by monsoon precipitation mainly concentrated in South China in June, and moved northward to the Yangtze River valley in July (Ding \& Chan 2005; Wang 2006; Huang et al., 2012), this will cause 56 months and 78 months in southern China, extreme precipitation reasons are different, therefore, this paper studies the summer extreme precipitation in southern China which divided into early rainy season (MJ) and late rainy season (JA).

The precipitation in the early rainy season is mainly influenced by the frontal 
system of the large-scale westerly belt, and the extreme precipitation is dominated by the rainstorm in the warm region (Zhao et al., 2008). The traditional frontal precipitation occurs on the cold side, clear weather on the warm side, and heavy rain on the warm front. The temperature gradient in the warm zone before the front is not obvious, and the low level jet (Ling, 2006) often accompanies the heavy rain. $75 \%-80 \%$ of the heavy rain in early rainy season in South China be related to the low-level jet, especially the low-level southwest jet. The low-level southwest jet carries with it the southern warm moist air, which increases the instability of atmospheric stratification and provides sufficient water vapor, because it is easy to develop into strong convection and rainstorm when disturbed and uplifted (Tao, 1980). Compared with the early rainy season, the late rainy season extreme precipitation is related to the weather system from the tropics, mainly influenced by the tropical weather systems such as the Intertropical Convergence Zone and tropical cyclones (Wu et al., 1990), such as easterly waves, tropical cyclones and the northward propagation of ISO, with strong convective activities and typhoon precipitation, there are obvious interannual variations (Wang, 2005).

The factors that influence the interannual variation of summer extreme precipitation in South China are usually related to EASM. South China is located between Eurasia and Pacific Ocean, and the exchange of heat and cold between land and sea can change the large-scale atmospheric circulation, more water vapor is transported from the oceans to the continents (for example, Wu \& Qian, 2003). The Northwest Pacific (WNP) during the El Nino decay year strengthened and extended to the west, enhanced the East Asian summer monsoon circulation, and caused the precipitation reduction in South China Yangtze River basin more precipitation (Chang et al., 2000; Yang \& Sun, 2005; Bao, 2007). The SST change of tropical Io is also an important change to the summer precipitation of SC. The Indian Ocean dipole (IOD: Saji et al., 1999) is another major pattern of tropical SST anomalies. Tang et al., (2008) indicate that IOD is positive, summer precipitation in South China is on the high side, IOD is negative, precipitation decreases.

There are great differences in the extreme precipitation events in rainy season around South China, and their spatial and temporal distribution, abnormal distribution and possible influencing factors have their own characteristics ( $\mathrm{Li}$ et al., 2002). However, previous studies have divided the early rainy season into April-June and the late rainy season into July-September. In fact, the onset of the Hainan monsoon in May marks the beginning of the East Asian summer monsoon. The rainy season in South China generally lasts from May to August, in the study of summer extreme precipitation in South China, May-June is the early rainy season and July-August is the late rainy season. In the study, the percentile method is used to characterize the extreme precipitation, and the temporal and spatial variation and abnormal distribution characteristics of the total amount and frequency of extreme precipitation in the early and late rainy seasons in South China are compared and analyzed, the relationship between the variation 
of extreme precipitation in the early and late rainy season and the anomalies of atmospheric circulation, Pacific Ocean and Indian Ocean SSTA is analyzed, and the possible reasons for the difference between the early and late rainy season extreme precipitation events in South China are discussed, deepening our understanding of summer extreme precipitation in South China will help us to analyze and predict the changes of summer extreme precipitation in South China under the global warming environment.

\section{Data and Methods}

The daily precipitation data from 756 stations in China from 1979 to 2014 were used in this study. The grid data used in this study include NCEP-NCAR global reanalysis data from 1979 to 2014 and NOAA Extended Reconstructed SST V4. The quality of daily precipitation data of the control station is controlled to eliminate the stations lacking of measured data in the scope of study.

The conventional methods used in this study include correlation analysis and univariate linear regression. Because of the focus on interannual variations, the interannual components of all data are extracted by using Fourier filter to filter out the waves of more than 10 years and remove the linear trend.

\subsection{Study Area}

Based on the daily precipitation data of 756 stations from 1979 to 2014 provided by the National Meteorological Information Center of China, this paper selects $\left(106-120^{\circ} \mathrm{E}, 20-28^{\circ} \mathrm{N}\right)$ as the study area. Finally, 88 stations are selected to represent South China, and the distribution of stations is shown in Figure 1. Considering the particular sources of moisture in Hainan (Ding et al., 2009), this article omits the Hainan site. Figure 1(a) is the spatial distribution of stations in South China, which is defined by Red Line.

\subsection{Sampling and Analyses}

ETCCDI (Expert Team on Climate Change Detection and Indices) index: the expert group on climate change detection and indicators has defined 27 alternative climate indexes, mainly focusing on the description of extreme events, including 16 temperature indexes and 11 precipitation indexes.

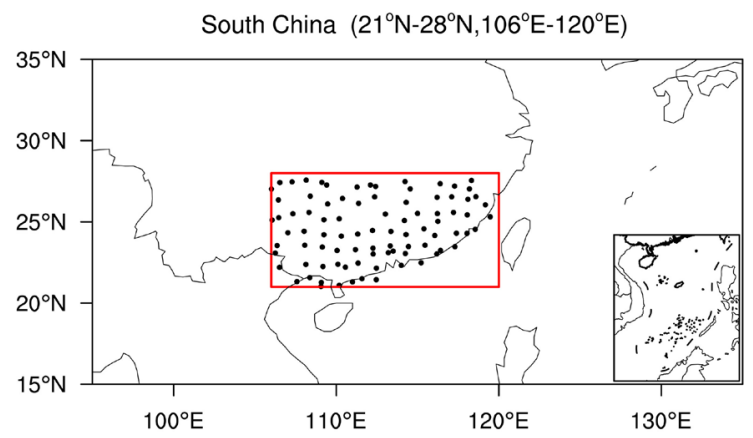

Figure 1. Distribution of observation stations (dark dots) in SC (red box). 
In view of the fact that the average daily precipitation in June in South China can reach $8 \mathrm{~mm}$ (Qin et al., 2013), R20, R95p and R99p can be selected as the internationally accepted indicators of ETCCDI, which are suitable for the interannual variation of frequency and intensity of summer extreme precipitation in South China. They represent the days with daily precipitation exceeding $20 \mathrm{~mm}$, the total precipitation with daily precipitation exceeding 95\% quantile and the total precipitation with daily precipitation exceeding 99\% quantile (Zhang et al., 2011). In this study, the total amount of extreme precipitation (R95p) and the frequency of extreme precipitation are selected as the main indicators to study the characteristics of extreme precipitation in South China. The extreme precipitation index and its definition used in this paper (Table 1).

The definition of extreme precipitation events, this paper adopts the international general percentile method, firstly, the precipitation below $1 \mathrm{~mm}$ is removed, and the daily precipitation in the early rainy season (MJ) and late rainy season (J A) of each station in South China from 1979 to 2014 is arranged in ascending order, the 36-year average of the 95th percentile of the series is defined as the threshold of extreme precipitation events in South China. The calculation of precipitation in the 95th percentile (Bonsal et al., 2001) is as follows.

Set the precipitation sequence in ascending order $X_{1}, X_{2}, X_{3}, \cdots, X_{m}, \cdots, X_{n}$, the probability of a value less than or equal to $X_{m}$ is $P=(m-0.31) /(n+0.38)$.

Among them, $\mathrm{M}$ is the sequence number of $\mathrm{XM}, \mathrm{N}$ is the number of precipitation sequence, $\mathrm{N}=61$ in the early rainy season and $\mathrm{N}=62$ in the late rainy season, that is, the total number of days of $\mathrm{MJ}$ and Ja in a year. The 95th percentile is the corresponding $\mathrm{XM}$ value of $\mathrm{P}=95 \%$. The value at the 95 th percentile is a linear interpolation of ordered XM and XM + 1 (Yang et al., 2008).

From 1979 to 2014, the mean spatial distribution of extreme precipitation threshold (Figure 2(a), Figure 2(b)) in the early and late rainy season in South China shows that the distribution of extreme precipitation threshold in the early and late rainy season has obvious regional difference. The early rainy season threshold is larger than the late rainy season as a whole, and the early rainy season threshold is larger in central Guangdong and coastal areas, northern Guangxi and southeastern coastal areas, northern Fujian and western Jiangxi, the thresholds of extreme precipitation in the north of Guangxi and at the junction of Guangdong and other provinces are relatively small, and the regions with large thresholds of extreme precipitation in the late rainy season are mainly concentrated in the southern coastal areas, while other regions are relatively small.

Table 1. The statistical indices and their definitions of extreme precipitation selected by this paper.

\begin{tabular}{clc}
\hline Indicator name & \multicolumn{1}{c}{ Definition } & Unit \\
\hline $\begin{array}{c}\text { Total precipitation } \\
\text { extremes }\end{array}$ & $\begin{array}{l}\text { Daily precipitation higher than the 95th percentile total } \\
\text { precipitation }\end{array}$ & mm \\
$\begin{array}{c}\text { Extreme precipitation } \\
\text { frequency }\end{array}$ & $\begin{array}{l}\text { The ratio of the number of days above the 95th percentile } \\
\text { to the total number of days }\end{array}$ & $\%$ \\
\hline
\end{tabular}




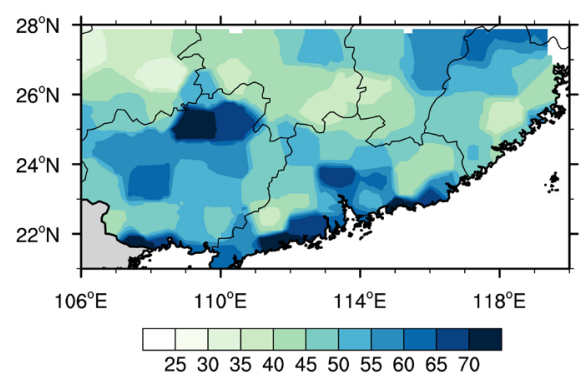

(a)

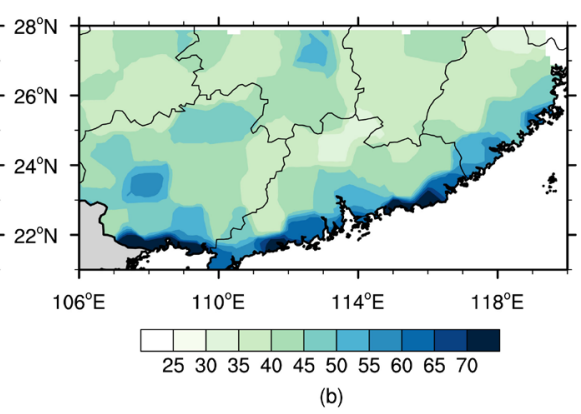

(b)

Figure 2. The spatial distribution of extreme rainfall threshold $(\mathrm{mm})$ in rainy season (May-August) of 50 meteorological stations of South China from 1979 to 2014. (a) MJ; (b) JA.

As shown in Table 2, the regional average threshold of the early rainy season is larger than that of the late rainy season, and the maximum and minimum of the relative threshold of the stations are both larger than that of the early rainy season. This shows that although the early rainy season threshold of South China is larger than that of the late rainy season as a whole, the maximum value of the late rainy season threshold is higher than that of the early rainy season.

\section{Results and Discussion}

\subsection{Temporal Variation of Extreme Precipitation Early and Late Rainy Season in South China}

Because of the particularity of summer precipitation in South China, many scholars usually divide the summer precipitation in South China into early rainy season (MJ) and late rainy season (JA). Figure 3 shows the time series of the SC extreme precipitation indices in MJ and JA. It is clear that the two indices have large interannual variations, but share little coherence (0.07). Therefore, when we study the extreme precipitation in summer in South China, we also divide it into early rainy season and late rainy season.

When studying regional extreme precipitation, we could not simply take the day when the precipitation exceeds the threshold as the total amount of extreme precipitation representing the whole region. For example, the extreme precipitation event in South China through the 95\% quantile threshold has a total of 1634 days before the rainy season, there are 1722 days in the late rainy season, and 2196 days in the early rainy season and 2232 days in the late rainy season in South China. Therefore, it takes several stations to have an extreme precipitation event to define the day as an extreme precipitation event. Typically defined as more than $10 \%$ of sites happening at the same time. There are 88 stations in South China in the study more than 8 stations can be defined as regional extreme precipitation events. The number of extreme precipitation events is 430 cases in the early rainy season and 249 cases in the late rainy season. Therefore, the extreme precipitation events can be regarded as the extreme precipitation events in the whole South China region, and further time scale analysis can be carried out. 


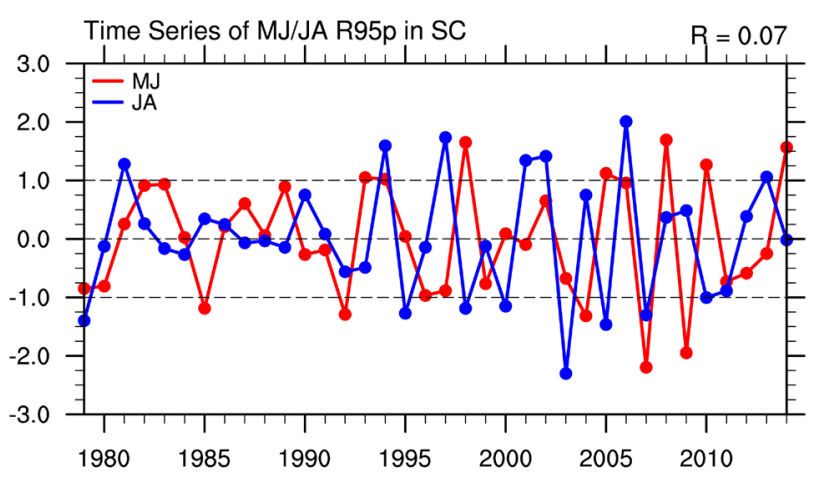

Figure 3. Time series of normalized region-mean extreme precipitation anomalies in SC in MJ (red) and JA (blue).

Table 2. Thresholds of extreme precipitation during rainy season in South China.

\begin{tabular}{cccc}
\hline Name & Max & Min & Average \\
\hline early rainy seasons & 88.4 & 30.1 & 52.0 \\
late rainy seasons & 96.2 & 33.3 & 47.3 \\
\hline
\end{tabular}

In the study, the total amount and frequency of extreme precipitation in rainy season from 1979 to 2014 are calculated. It can be seen from Figure 4 (Figure 4(a), Figure 4(b)) that the total amount and frequency of extreme precipitation in rainy season have obvious interannual variation and upward trend, which indicates that the extreme precipitation events are frequent and the total amount of precipitation increases in the whole rainy season in South China. In the early rainy season (MJ). frequent occurrence of extreme precipitation events (Standardization higher than 1) mainly occurred in 1993, 1994, 1998, 2005, 2008, 2010, 2014, and the rare occurrence events (Standardization less than -1) mainly occurred in 1985, 1992, 2004, 2007, 2009. The most frequent years of extreme precipitation events in early rainy season (JA) were 1981, 1994, 1997, 2001, 2002, 2006 and 2013, and the least frequent years were 1979, 1995, 1998, 2000, 2003, 2005, 2007, 2010. From the results of wavelet analysis (Figure 2(c) and Figure $2(d)$ ), it can be seen that there are mainly 2 cycles of extreme precipitation frequency in the early rainy season. One is the interannual cycle of $3-5$ years, the time domain of energy fluctuation is mainly from the late 90 's to the early 2000s, and the quasi-biennial cycle (quasi-biennial oscillation) appears after the early 2000s. The late rainy season has a 6 - $8 \mathrm{~A}$ cycle, and the time domain of its fluctuation energy is mainly distributed after 1990s. There are different periods early and late rainy season in South China, and the two periods are mainly after the 1990s.

\subsection{Spatial Distribution Difference of Extreme Precipitation Early and Late Rainy Season in South China}

In order to reveal the spatial distribution characteristics of extreme precipitation early and late rainy season, this paper analyzes the spatial distribution of the 

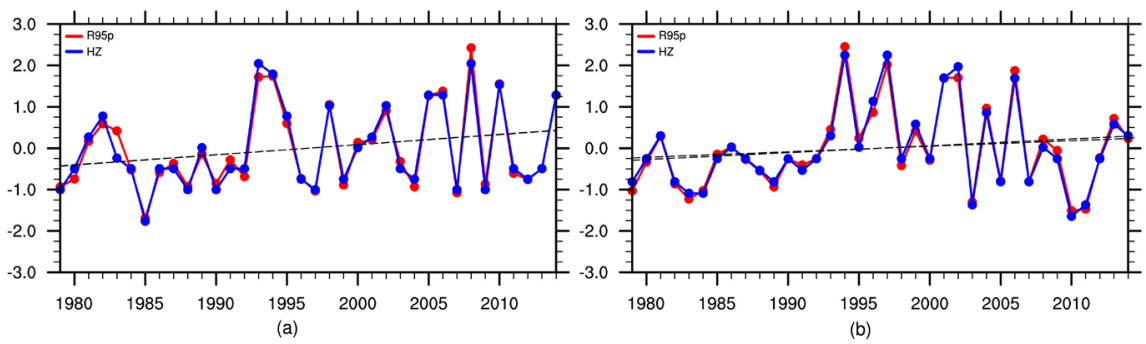

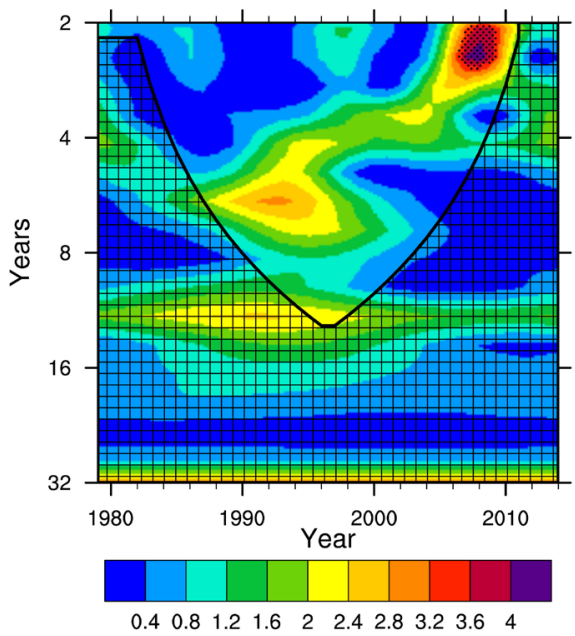

(c)

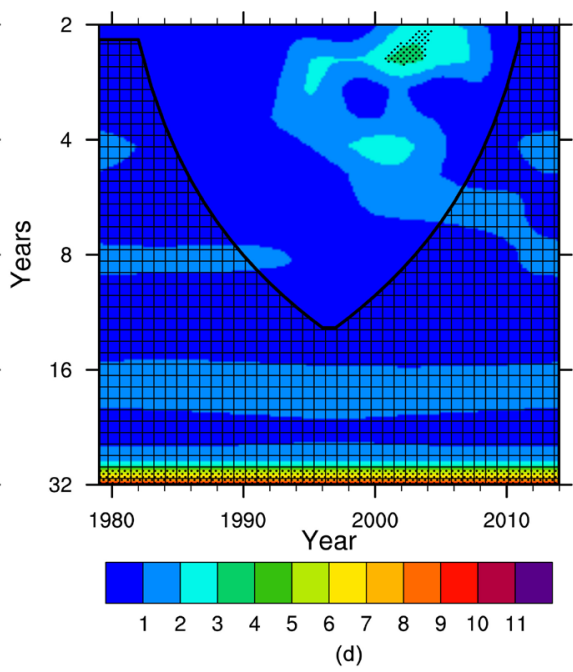

Figure 4. The standardized time series and wavelet analysis of region averaged extreme rainfall in the early $((\mathrm{a}),(\mathrm{c}))$ and latter ((b), (d)) rainy season of South China. (a) MJ; (b) JA; (c) MJ; (d) JA.

average total amount of extreme precipitation (Figure 5(a), Figure 5(b)) and the frequency of extreme precipitation (Figure 5(c), Figure 5(d)) in 36 years early and late rainy season in South China. It is similar to the spatial distribution of mean annual heavy precipitation (Figure 2(c), Figure 2(d)) early and late rainy season in South China. The local characteristics of extreme precipitation frequency are more obvious, except for Guizhou and Jiangxi, there are high value centers of heavy precipitation frequency in other provinces, which indicates that the frequency of heavy precipitation in most areas of South China is on the high side. The extreme precipitation indices selected in this paper can reflect the spatial distribution characteristics of extreme precipitation in rainy season, and the frequency of extreme precipitation affects the spatial distribution of total precipitation in summer. The correlation coefficient between regional average total precipitation and extreme precipitation frequency is higher than 0.9 , significant at the $90 \%$ confidence level. It shows that the extreme precipitation index selected in this paper has a good indication for the time variation of the total precipitation in the whole region of South China in the late rainy season.

The maximum value areas of extreme precipitation (Figure 3(a)) in the early rainy season are located in the northeast of Guangxi and the Central and southern coastal areas of Guangdong. Most of the extreme precipitation frequency (Figure 3(c)) in Guangdong and Guangxi is on the high side, the high value area 

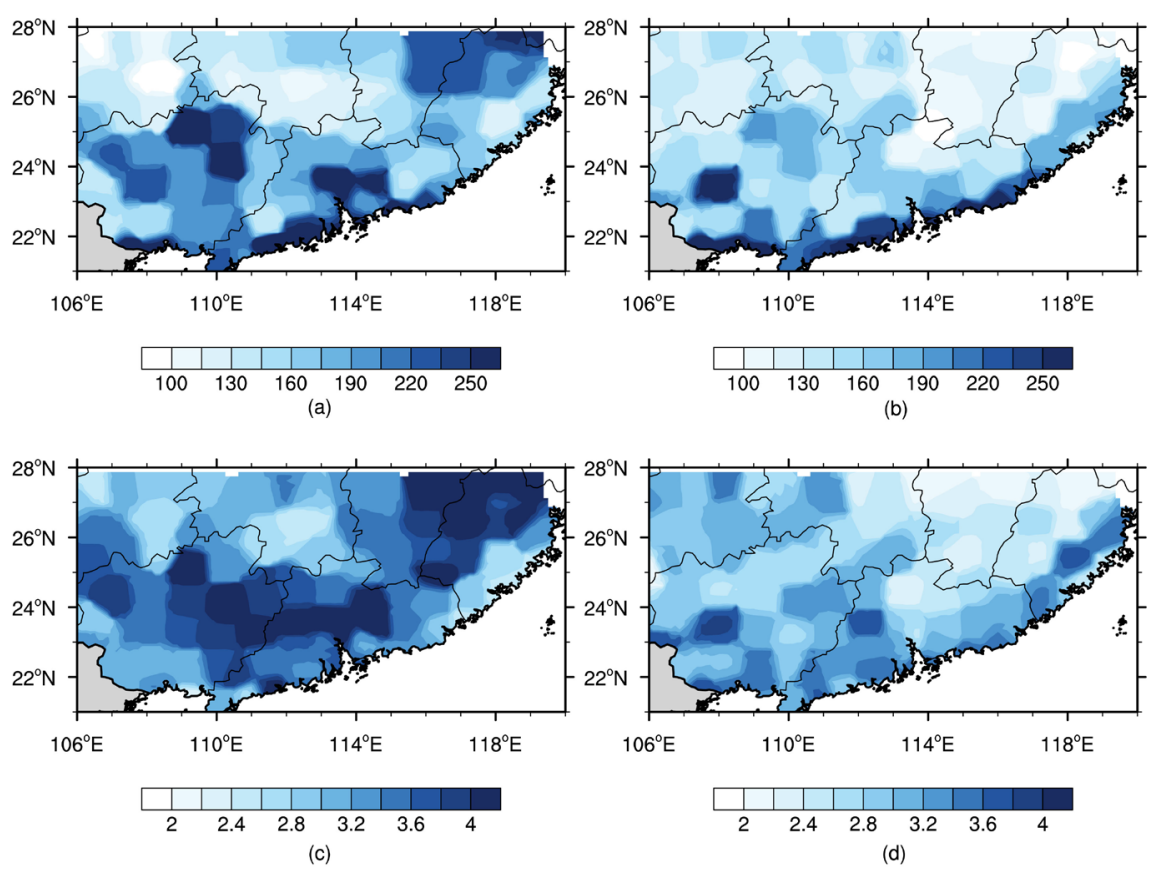

Figure 5. The spatial distribution of extreme rainfall index in South China; (a) extreme rain amount $(\mathrm{mm})$ in the early rainy season; (b) extreme rain amount $(\mathrm{mm})$ in the latter rainy season; (c) extreme rainfall frequency (\%) in the early rainy season; (d) extreme rainfall frequency (\%) in the latter rainy season. (a) MJ; (b) JA; (c) MJ_Frequency; (d) JA_Frequency.

is basically consistent with the high value area of extreme precipitation. The maximum value of extreme precipitation (Figure 3(b)) in the late rainy season is higher than that in the early rainy season, mainly in the coastal areas of Guangxi, Guangdong and Hainan, and the large value falling area of the extreme precipitation frequency (Figure $3(\mathrm{~d})$ ) is basically the same. In a word, the temporal and spatial distribution of extreme precipitation events in rainy season are different in South China.

\subsection{Effects of Tropical SST on Extreme Precipitation in Rainy Season in South China}

The tropical Indian Ocean, located in the upper reaches of China, is the main source of the circum equatorial intraseasonal oscillation as well as the main source of summer precipitation in Asia. The main modes of SST anomalies in the tropical Indian Ocean are Basin mode (IOBM) and dipole mode (IOD). The positive phase IOBM can cause the East Asian summer monsoon to strengthen, the Yangtze Plain precipitation to increase, and the South China precipitation to reduce. IOD is an east-west plus-minus SSTA dipole phenomenon in the tropical Indian Ocean. It usually occurs and grows in late spring/early summer, matures in autumn and then decays. The summer precipitation in the monsoon region of China be affected by IOD. When IOD is in positive phase, the summer precipitation in Yangtze Plain decreases, but the summer precipitation in South China increases. The main mode of SST anomaly over the tropical Pacific is 
ENSO. The influence of ENSO development year and attenuation year on East Asian summer monsoon is different, and the influence of attenuation year is more serious. The influence of Enso on the East Asian monsoon region is mainly through the monsoon anticyclone in the northwest Pacific.

The Tropical SST has an effect on the annual variation of the intensity and frequency of extreme precipitation in rainy season around South China (Figure 2(a), Figure 2(b)). By using the SST of South China precipitation or extreme precipitation to return to the Global SST, and the SST of R95P precipitation in the early and late rainy season and the early and late rainy season to return to the same SST region, the extreme precipitation in the early rainy season is mainly influenced by the sea temperature region IO $\left(50^{\circ}-100^{\circ} \mathrm{E}, 10^{\circ} \mathrm{S}-20^{\circ} \mathrm{N}\right)$ excited by IOBM, The Matsuno-Gill response region $\left(10^{\circ} \mathrm{S}-10^{\circ} \mathrm{N}, 170^{\circ} \mathrm{E}-\right.$ $140^{\circ} \mathrm{W}$ ) is mainly stimulated by the dipole SST MC in the late rainy season by the cold SST $\left(10^{\circ} \mathrm{S}-10^{\circ} \mathrm{N}, 90^{\circ}-140^{\circ} \mathrm{E}\right)$ near the oceanic continent and the warm SST in the equatorial central Pacific.

The circulation anomaly which causes the increase of the intensity of the extreme precipitation in South China is almost opposite (Figure 6(a), Figure 6(b)). If we consider the extreme precipitation anomaly in the rainy season as a whole, it not only makes the circulation anomaly cancel each other, it would also significantly reduce signals in key areas of the tropical oceans. There is an anticyclonic circulation anomaly in the northwest Pacific during the early rainy season when the extreme precipitation increases. The anticyclone may be excited by the tropical Indian Ocean IOBM. When the extreme precipitation in the late rainy season increases, there is a cyclonic circulation anomaly in the northwest Pacific, which is more north than the anticyclone anomaly in the early rainy season. The cold SST near the oceanic continent and the warm SST in the equatorial central Pacific can trigger the response of Matsuno-Gill to the cyclonic circulation anomaly in the northwest Pacific Ocean.

\section{Conclusion}

Based on the daily precipitation data of 88 stations in South China from 1979 to 2014, the percentile method is used to define the extreme precipitation in the rainy season of South China, by means of Fourier filter and wavelet analysis, the
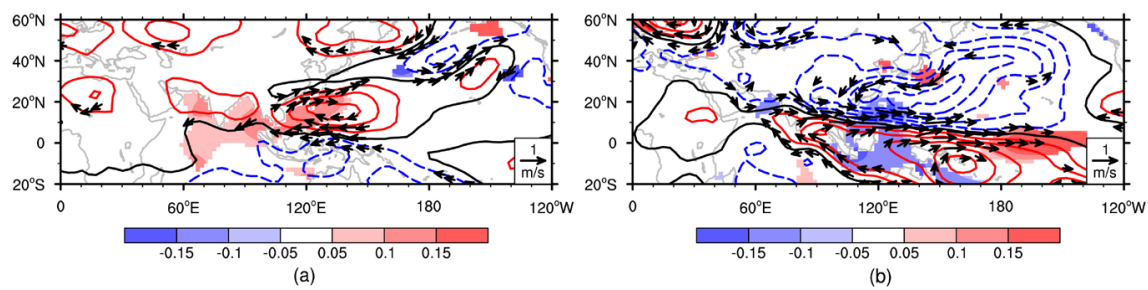

Figure 6. (a) MJ and (b) JA anomalies of (a), (b) SST (shading; 8C), horizontal wind (vectors; ms21), and Stream function (contours; $\mathrm{m} 2 \mathrm{~s} 21$ ) at $850 \mathrm{hPa}$ to have a standard deviation of 1 . Only the anomalies significant at the $90 \%$ confidence level for SST and wind are shown in (a) and (b).Wind anomalies less than $0.4 \mathrm{~ms} 21$ are not shown. 
temporal and spatial variation of extreme precipitation events in the early and late rainy seasons in South China and the possible causes are analyzed. The main conclusions are as follows:

On the time scale, there are obvious interannual variations of extreme precipitation early and late rainy season in South China, and the total amount and frequency of extreme precipitation are rising, but the change cycle is different. The early rainy season is mainly $3-5$ years, and the late rainy season is mainly 6 - 8 years.

On the spatial scale, the spatial distribution of extreme precipitation is similar to that of multi-year mean heavy precipitation (Figure 2(a), Figure 2(b)). The local characteristics of extreme precipitation frequency are more obvious, except Guizhou and Jiangxi, all other provinces have high value centers of heavy precipitation frequency, which indicates that the frequency of heavy precipitation in most areas of South China is on the high side as a whole. Most of the extreme precipitation occurred in the northeast of Guangxi and the middle of Guangdong in the early rainy season, and most of the extreme precipitation occurred in the coastal areas in the late rainy season.

The main reasons for the differences in the temporal and spatial variations of the extreme precipitation are as follows: the circulation anomalies causing the increase in the intensity of the extreme precipitation in South China during the rainy season are almost opposite, if we consider the extreme precipitation anomaly early and late rainy season as a whole, it will not only make the circulation anomaly cancel each other, but also will weaken the signal of the key area of the tropical ocean. The increase of the extreme precipitation in early rainy season is due to the anticyclonic anomaly over South China triggered by IOBM, which results in an increase of the water vapor inflow from the southern boundary of South China, and the increase in the late rainy season is due to the cyclonic anomaly over South China triggered by the northwest Pacific Dipole SST, the northeasterly air current in the northwest of China can help to reduce the water vapor outflow from the northern border of South China, thus increasing the water vapor in the whole south China region, resulting in higher atmospheric instability and more extreme precipitation.

There are many factors affecting the summer extreme precipitation in South China, not only the SST anomalies in the Indian Ocean and the Pacific Ocean mentioned in the study, but also the intensity and westward extension of the Western Pacific subtropical high, the strengthening of the cold high in the north, the deepening and development of the East Asian Trough, which are conducive to the southward expansion of the cold air in the north. It is necessary to further explore which factors play a leading role, or whether these factors interact with each other, resulting in the enhancement of summer extreme precipitation in South China.

\section{Conflicts of Interest}

The authors declare no conflicts of interest regarding the publication of this paper. 


\section{References}

Bao, M. (2007). The Statistical Analysis of the Persistent Heavy Rain in the Last 50 Years over China and Their Backgrounds on the Large Scale Circulation. Chinese Journal of Atmospheric Sciences, 31, 779-792. (In Chinese)

Bonsal, B. R., Zhang, X., Vincent, L. A., \& Hogg, W. D. (2001). Characteristics of Daily and Extreme Temperatures over Canada. Journal of Climate, 14, 1959-1976. https://doi.org/10.1175/1520-0442(2001)014\%3C1959:CODAET\%3E2.0.CO;2

Chang, C.-P., Zhang, Y., \& Li, T. (2000). Interannual and Interdecadal Variations of the East Asian Summer Monsoon and Tropical Pacific SSTs. Part I: Roles of the Subtropical Ridge. Journal of Climate, 13, 4310-4325. https://doi.org/10.1175/1520-0442(2000)013\%3C4310:IAIVOT\%3E2.0.CO;2

Ding, J. L., Xu, Z. S., Fei, J. F. et al. (2009). Analysis of the Definition of the Onset and Ending Dates of the Annually First Rainy Season in South China and Its Interannual Variation Characteristics. Journal of Tropical Meteorology, 25, 59-65.

Ding, Y., \& Chan, J. C. L. (2005). The East Asian Summer Monsoon: An Overview. Meteorology and Atmospheric Physics, 89, 117-142. https://doi.org/10.1007/s00703-005-0125-Z

He, Y. H., \& Jin, Z. H. (1998) Oscillation and Distribution of Rainfall during Second Rainy Season in South China. Journal of Tropical Meteorology, 14, 359-363.

Huang, R., Chen, J., Wang, L., \& Lin, Z. (2012). Characteristics, Processes, and Causes of the Spatio-Temporal Variabilities of the East Asian Monsoon System. Advances in Atmospheric Sciences, 29, 910-942. https://doi.org/10.1007/s00376-012-2015-x

Lau, K.-M., \& Yang, S. (1997). Climatology and Interannual Variability of the Southeast Asian Monsoon. Advances in Atmospheric Sciences, 14, 141-162. https://doi.org/10.1007/s00376-997-0016-y

Li, J.N., Wang, A. Y., Meng, W. G., Fan, Q., Feng, R. Q., \& Hou, E. B. (2002). The Climatological Characteristics of Precipitation of the Pre-Summer Rainy Season and Second Rainy Season in Guangdong Province. Acta Scientiarum Naturalium Universitatis Sunyatseni, 41, 91-95.

Liang, J. Y., \& Wu, S. S. (2001) Formation Reasons of Drought and Flood in the Rain Season of Guangdong and Preceding Impact Factors. Journal of Tropical Meteorology, 17, 97-108.

Ling (2006). Technical Manual of Weather Forecast of Guangdong Province (pp. 119-150). Beijing: Meteorological Press.

Qin, S., Lu, R., \& Li, C. (2013) Large-Scale Circulation Anomalies Associated with Interannual Variation in Monthly Rainfall over South China from May to August. Advances in Atmospheric Sciences, 31, 273-282.

https://doi.org/10.1007/s00376-013-3051-x

Saji, N. H., Goswami, B. N., Vinayachandran, P. N., \& Yamagata, T. (1999). A Dipole Mode in the Tropical Indian Ocean. Nature, 401, 360-363.

https://doi.org/10.1038/43854

Tang, W., Sun, Z., \& Tan, G. (2008). Effect of Indian Ocean Dipole on Rainfall Anomaly in South of China. Journal of Nanjing Institute of Meteorology, 31, 836-843. (In Chinese)

Tao, Z. Y. (1980). The Structure and Formation of the Moist Jet Stream. Journal of Meteorological, 38, 331-340. 
Wang, Z. W., Tang, H. Y., \& Li, F. (2005). Analysis of Changing Characteristics of Floods in South China during the Recent 50 Years. Journal of Tropical Meteorology, 21, 87-92.

Wang, B. (2006). The Asian Monsoon. Springer-Praxis (845 pp.). Berlin, Heidelberg: Springer. https://doi.org/10.1007/3-540-37722-0

Wang, B., \& Wu, R. (1997). Peculiar Temporal Structure of the South China Sea Summer Monsoon. Advances in Atmospheric Sciences, 14, 177-194.

https://doi.org/10.1007/s00376-997-0018-9

Wu, S. S., Huang, C. C., \& Xue, H. X. (1990) Interannual Variation of Precipitation during the Second Rainy Season in South China. Journal of Tropical Meteorology, No. 4, 348-356.

Wu, T.-W., \& Qian, Z.-A. (2003). The Relation between the Tibetan Winter Snow and the Asian Summer Monsoon and Rainfall: An Observational Investigation. Journal of Climate, 16, 2038-2051. https://doi.org/10.1175/1520-0442(2003)016\%3C2038:TRBTTW\%3E2.0.CO;2

Xu, L. (1994). Heavy Losses in South China and Large Arid Area in North and Northeast China. Meteorological Monthly, 9, 62-63. (In Chinese)

Yang, H., \& Sun, S. (2005). The Characteristics of Longitudinal Movement of the Subtropical High in the Western Pacific in the Pre-Rainy Season in South China. Advances in Atmospheric Sciences, 22, 392-400.

Yang, J., Jiang, Z. H., Wang, P. X., \& Chen, Y. S. (2008). Temporal and Spatial Characteristic of Extreme Precipitation Event in China. Climatic and Environmental Research, 13, 75-83.

https://xueshu.baidu.com/usercenter/paper/show?paperid=61ef595cbb1d19c0650a777b 754 aacba\&site $=$ xueshu se

Zhang, X., Alexander, L., Hegerl, G. C., Jones, P., Tank, A. K., Peterson, T. C. et al. (2011). Indices for Monitoring Changes in Extremes Based on Daily Temperature and Precipitation Data. WIREs Climate Change, 2, 851-870. https://doi.org/10.1007/BF02918752

Zhao, Y. C., Li, Z. C., \& Xiao, Z. N. (2008). Comparative Analysis of Rainstorm Cases in South China Front and Warm Area. Meteorological Science and Technology, 36, 47-54.

Zhu, C. W., Lee, W.-S., Kang, H., \& Park, C.-K. (2005). A Proper Monsoon Index for Seasonal and Interannual Variations of the East Asian Monsoon. Geophysical Research Letters, 32, Article ID: L02811. https://doi.org/10.1029/2004GL021295 